\title{
The effect of method, standard and sample components on the total antioxidant capacity of commercial waters assessed by optical conventional assays
}

\author{
Felismina T.C. Moreira, Joana R.L. Guerreiro, Rui Barros, M. Goreti F. Sales
}

\begin{abstract}
The total antioxidant capacity (TAC) of 28 flavoured water samples was assessed by ferric reducing anti- oxidant potential (FRAP), oxygen radical absorbance capacity (ORAC), trolox equivalent antioxidant capacity (TEAC) and total reactive antioxidant potential (TRAP) methods. It was observed that flavoured waters had higher antioxidant activity than the corresponding natural ones. The observed differences were attributed to flavours, juice and vitamins. Generally, higher TAC contents were obtained on lemon waters and lower values on guava and raspberry flavoured waters. Lower and higher TACs were obtained by TRAP and ORAC method, respectively. Statistical analysis suggested that vitamins and flavours increased the antioxidant content of the commercial waters.
\end{abstract}

Keywords

Total antioxidant capacity, FRAP, TEAC, ORAC, TRAP, Commercial waters

\section{Introduction}

Most living organisms have developed complex endogenous and exogenous antioxidant systems to counteract and prevent the deleterious effects of reactive oxygen species (ROS) (Cao \& Prior, 1998). ROS (such as, hydrogen peroxide, $\mathrm{H}_{2} \mathrm{O}_{2}$; hydroxyl radical, $\mathrm{HO}$, and superoxide radical, $\mathrm{O}_{2}{ }^{-}$) induce damage to the cells by reacting with biomolecules (proteins, lipids, among others) and cause serious lesions on DNA (Halliwell, 2009). Therefore, antioxidants appear to be very important in the prevention of many diseases, like as, atherosclerosis, diabetes mellitus, neurodegenerative disorders and certain types of cancer (Benherlal \& Arumughan, 2008; Chen, Wang, Qi, \& Xie, 2007).

Endogenous antioxidant systems include enzymes, such as, superoxide dismutase, glutathione peroxidase, glutathione reductase, glutathione-S-transferase and catalase (Augustin, Wiswedel, Noack, Reinheckel, \& Reichelt, 1997; Cao, Alessio, \& Cutler, 1993). An additional protection can be provided by exogenous antioxidant compounds, such as, vitamins (A, E, C, b-carotene), phenolic compounds, minerals (selenium, zinc) or proteins (transferrin, ceruloplasmin, albumin) (Ferreira, Baptista, Vilas-Boas, \& Barros, 2007). Increasing intake of dietary antioxidants may help to maintain an adequate antioxidant status and, therefore, the normal physiological functions of a living system. Some functional foods, vegetables, fruits and whole-grain cereals are good sources of exogenous antioxidants (Almajano, Carbó, Jiménez, \& Gordon, 2008; Frankel, 2007; Huang, Wang, Eaves, Shikany, \& Pace, 2009; Lee et al., 2009). Recently, to answer to consumer's preferences and considering that water is the most consumed drink all over the world, fla- voured waters were developed and commercialised. Flavoured waters are produced from mineral and spring waters. In the first semester of 2009, 6.23 million litters of this kind of water were consumed by Portuguese population (ANIRSF, 2009). This kind of water consist in the addition of flavours, juices and sugar or sweet- eners that provide water singular tastes and smells appreciated by

consumers. Considering that flavours/aromas are fruit extracts, they should contain natural antioxidants, transferring them into the bottled water. So, drinking this type of water can increase the daily intake of natural exogenous antioxidants and may contribute to the protective system against ROS. However, there are no reports concerning the antioxidant capacity properties of these waters, although their macro and micromineral compositions are known. So, the presented research work is meant to find advantages/disadvantages of the consumption of these beverages with regard to its total antioxidant capacity (TAC).

Several methods have been reported to assess TAC in biological and food samples, because of the difficulty in measuring each antioxidant component separately and the interactions among different antioxidant components in the samples. Ferric reducing antioxidant potential (FRAP) (Benzie \& Strain, 1999; Benzie \& Szeto, 1999; Griffin \& Bhagooli, 2004; Prior, Wu, \& Schaich, 2005; 

Pulido, Bravo, \& Saura-Calixto, 2000; Sánchez-Alonso, JiménezEscrig, Saura-Calixto, \& Borderías, 2007), trolox equivalent antioxidant capacity (TEAC) (Castro, Rogero, Junqueira, \& Carrapeiro, 2006; Pellegrini et al., 2003), oxygen radical absorption capacity (ORAC) (Cao et al., 1993; Ou, Hampsch-Woodill, \& Prior, 2001; Ou, Huang, Hampsch-Woodill, Flanagan, \& Deemer, 2002; Prior et al., 2005) and total reactive antioxidant potential (TRAP) (Ghiselli, Serafinni, Natella, \& Scaccini, 2000; Prior et al., 2005; SánchezMoreno, 2002) are examples of methods used to determine TAC. Mechanistically, these methods are based either on single electron transfer or hydrogen atom transfer reactions between an oxidant and a free radical (Sánchez-Moreno, 2002). Change of absorbance of either antioxidant or oxidant is measured by an ultraviolet-visible spectrophotometer for FRAP, TEAC and TRAP methods and spectrofluorimetry for ORAC method. Absorbance value is used for the quantification of the reducing capability of the antioxidant (Ou et al., 2002).

These analytical methods include several advantages: technically they are simple with good repeatability and reproducibility. These techniques are also adaptable for assay on both hydrophilic and lipophilic antioxidants. However, no single assay really provides the TAC of a particular sample. The comparison of data from different studies is also difficult. In this context, a primary factor to consider when selecting a method is the mechanism of reaction and its relationship to what might occur in the envisioned application. It is also advantageous to select methods that are commonly accepted, validated and standardised, with a large body of comparable data available in the literature. Thus, to elucidate a full profile of TAC of complex samples such as flavoured waters it is essential to use various analytical methods (Prior et al., 2005).

Furthermore, TAC values also depend on the antioxidant standard used as reference. Ascorbic acid, gallic acid and trolox are widely used for this purpose. Ascorbic acid or vitamin $\mathrm{C}$ is a powerful antioxidant because it can donate a hydrogen atom and form a relatively stable ascorbyl free radical. As a scavenger of reactive oxygen and nitrogen oxide species, ascorbic acid has shown to be effective against the superoxide radical ion, hydrogen peroxide, the hydroxyl radical and singlet oxygen (Weber, Bendich, \& Schalch, 1996). Trolox is a synthetic, hydrosoluble phenolic derivative of vitamin $\mathrm{E}$ and gallic acid is found both free and as part of tannins.

In the present study, the previously indicated methods were used to evaluate the TAC of all marketed waters found: 28 mineral and spring water samples, with flavours. Ascorbic acid, gallic acid and trolox were used as standards.

\section{Materials and methods}

\subsection{Standard and reagents}

Analytical grade chemicals were employed. Gallic acid, potassium persulphate monohydrate 2,4,6-tripyridyl-s-triazine (TPTZ), 6-hydroxy-2,5,7,8-tetramethylchroman-2-carboxylic acid (trolox) and 2,2-azinobis-(3-ethylbenzothiazoline-6-sulphonic acid) (ABTS), were obtained from Fluka. Ascorbic acid, sodium acetate trihydrate, glacial acetic acid, $\mathrm{FeCl}_{3} 6 \mathrm{H}_{2} \mathrm{O}$, dipotassium hydrogenphosphate anhydrous, phosphoric acid, hydrochloric acid were purchased from Merck. Fluorescein was obtained from Riedel-de Haën and 2,2-Azobis (2-methyl-propanimidamide) (AAPH) was purchased from Aldrich.

\subsection{Sampling procedure}

Water samples were collected from several local supermarkets and stored aside from light at $4{ }^{\circ} \mathrm{C}$. All waters found by that time were included in this study: 28 flavoured water samples (mineral and spring). Each brand included still or sparkling waters with different flavours and aromas. The natural water of each brand was always used as negative control. The gas was eliminated from the samples by sonication. Fig. 1 groups the sample distribution according to the labelled information, regarding the presence of vitamins, sweeteners and preservatives (no quantity was mentioned).

\subsection{FRAP assay}

FRAP assay measures the ability of antioxidants to reduce the ferric 2,4,6-tripyridyl-s-triazine complex [Fe(III)-(TPTZ) $\left.{ }_{2}\right]^{3+}$ to the intensely blue coloured ferrous complex $\left[\mathrm{Fe}(\mathrm{II})-(\mathrm{TPTZ})_{2}\right]^{2+}$, in acidic medium, with an absorption maximum at $593 \mathrm{~nm}$ (Benzie \& Strain, 1999; Benzie \& Szeto, 1999; Griffin \& Bhagooli, 2004; Prior et al., 2005; Pulido et al., 2000; Sánchez-Alonso et al., 2007). FRAP reaction detects compounds with redox potentials $<0.7 \mathrm{~V}$ (redox potential of $\mathrm{Fe}^{3+}$-TPTZ). So it cannot detect compounds that act by radical quenching ( $\mathrm{H}$ transfer), particularly thiols and proteins (Ou et al., 2002). Absorbance was measured on a Shimadzu 160-A spectrophotometer. The experiment was conducted at $37^{\circ} \mathrm{C}$ under $\mathrm{pH}$ 3.6 (to ensure Fe solubility). Blank trials were carried out in parallel. The working FRAP reagents were produced by mixing $300 \mathrm{mM}$ acetate buffer, $10 \mathrm{mM}$ TPTZ solution and $20 \mathrm{mM} \mathrm{FeCl} 36 \mathrm{H}_{2} \mathrm{O}$ in a 10:1:1 ratio before use and heated to $37{ }^{\circ} \mathrm{C}$. The $300 \mathrm{mM}$ acetate buffer was prepared with $3.1 \mathrm{~g}$ of acetic acid brought to $1 \mathrm{~L}$ with distilled water. TPTZ solution was prepared with $10 \mathrm{mM}$ TPTZ in $40 \mathrm{mM} \mathrm{HCl}$. These solutions were daily prepared. A mixture of $15001 \mathrm{~L}$ working FRAP solution, $13001 \mathrm{~L}$ acetate buffer and $2001 \mathrm{~L}$ water sample were added to a spectrophotometric cell. Absorbance readings were taken at $30 \mathrm{~s}$ and then every $20 \mathrm{~min}$ until minimal signal stabilisation. Calibration curves were traced for each time and analytical results were calculated for the corresponding measuring time. Final results were expressed in $1 \mathrm{M}$ of ascorbic acid.

\subsection{TEAC assay}

This method is based on the ability of antioxidant molecules to quench the long-lived radical cation $\mathrm{ABTS}^{+}$, a blue-green chromophore with typical maximum absorption at $734 \mathrm{~nm}$, compared with to that of trolox, a water-soluble vitamin $\mathrm{E}$ analog. The addition of antioxidants to the preformed radical cation reduces it to ABTS, determining a decolourisation (Pellegrini et al., 2003). A stable stock solution of $\mathrm{ABTS}^{+}$was produced by reacting a $7 \mathrm{mM}$ aqueous solution of ABTS with $2.45 \mathrm{mM}$ potassium persulphate diluted in phosphate buffer ( $\mathrm{pH}$ 7) and allowing the mixture to stand in the dark, at room temperature, for $12-16 \mathrm{~h}$ before use. At the beginning of each day, an $\mathrm{ABTS}^{+}$working solution (B) was obtained by dilution in phosphate buffer of the stock solution to an absorbance of $0.70 \pm 0.02$ a.u. Two thousand microlitres of this solution was added to $10001 \mathrm{~L}$ of sample solution. The absorbance of this final solution was read after $15 \mathrm{~min}$, at $734 \mathrm{~nm}$. TAC was expressed in $1 \mathrm{M}$ of trolox, ascorbic acid and gallic acid.

\subsection{ORAC assay}

ORAC measures the antioxidant inhibition of peroxyl radical induced oxidations and thus reflects classical radical chain breaking antioxidant activity by $\mathrm{H}$ atom transfer. In this assay, the peroxyl radical reacts with AAPH (radical) to form a non-fluorescent product, which can be quantified by spectrofluorimetry. TAC is determined by the decreased rate and amount of fluorescence decay over time (Cao et al., 1993; Ou et al., 2002; Prior et al., 2005). Sample $(3001 \mathrm{~L})$ and fluorescein $\left(10001 \mathrm{~L}, 14 \times 10^{-3} 1 \mathrm{M}\right)$ were added 

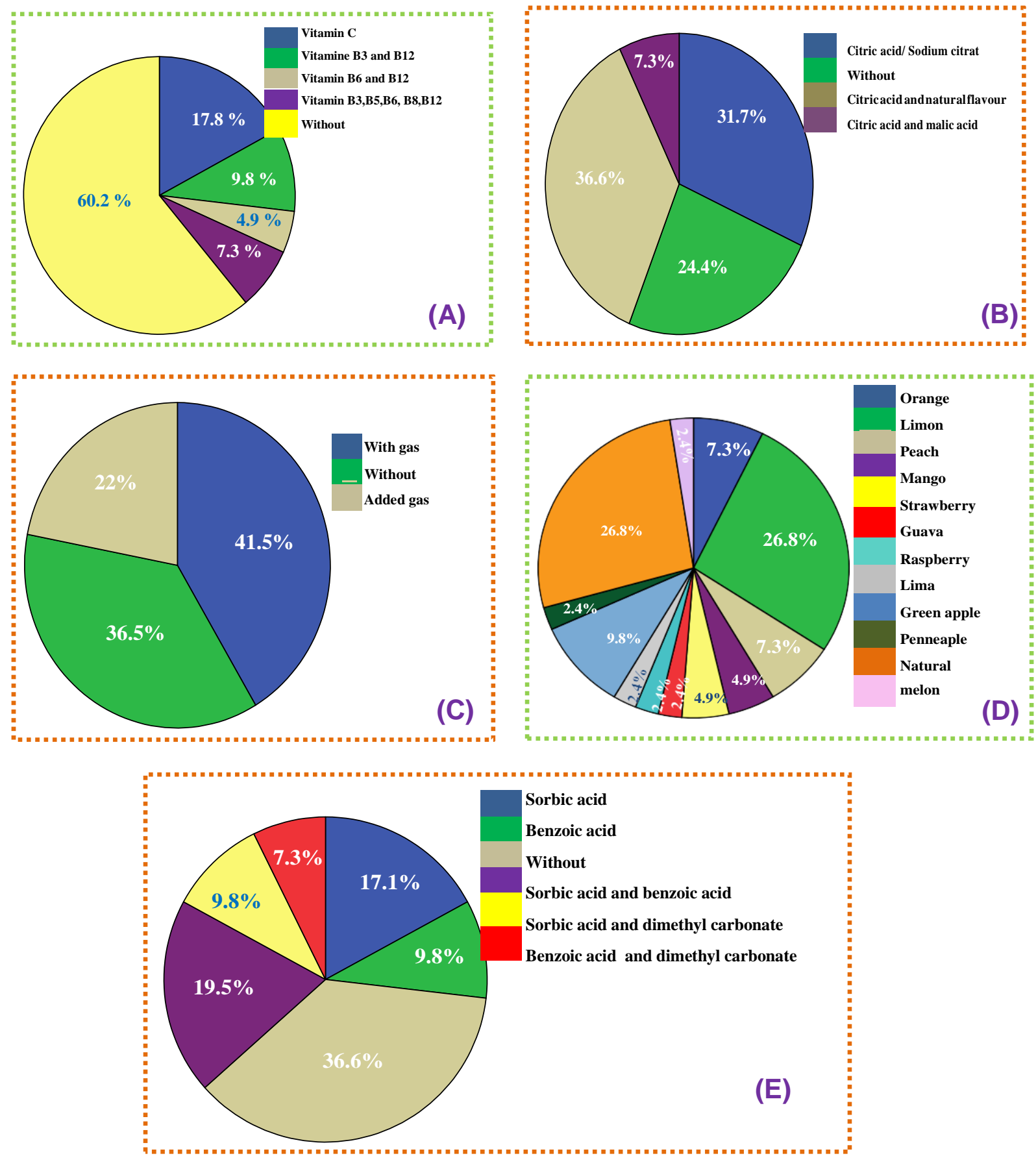

Fig. 1. Descriptive statistics of water labels, considering several factors: (A) vitamins; (B) preservatives; (C) gas; (D) flavour; and (E) acidity regulators.

to a spectrophotometric cell, and the mixture was incubated at $37{ }^{\circ} \mathrm{C}$ for $20 \mathrm{~min}$, followed by addition of $1700 \mathrm{1L}$ of radical solution (4.8 mM). Fluorescence was monitored in an AvaSpec 2048 fluorimeter with xenon lamp pulsed at 485 and $528 \mathrm{~nm}$ (excitation and emission wavelengths, respectively) until the final fluorescence was equal to $0.5 \%$ of the initial fluorescence. TAC was $\mathrm{ex}^{-}$ pressed in 1M of trolox, ascorbic acid and gallic acid. A linear correlation was found between antioxidant concentration and the area under curve (AUC) that was calculated as:

$$
\text { AUC }=1+f_{1} / f_{0}+f_{2} / f_{0}+f_{3} / f_{0}+\ldots f_{34} / f_{0}+f_{35} / f_{0}
$$

where $f_{0}$ is the initial fluorescence reading at $0 \min$ and $f_{i}$ is the fluorescence reading at time $i$.

\section{TRAP assay}

TRAP assay monitors the ability of antioxidant compounds to interfere with the reaction between peroxyl radicals and a target probe (Araki et al., 1999; Prior et al. 2005; Ghiselli et al., 2000). AAPH was used as the peroxyl-radical generator to start the reaction. The final reaction mixture for the assay contained $2 \mathrm{mMAAPH}$ and $751 \mathrm{M}$ ABTS in $50 \mathrm{mM}$ acetate buffer $(\mathrm{pH} 4.3)$. The reaction mixture was incubated at $45^{\circ} \mathrm{C}$ for $60 \mathrm{~min}$ and then brought to

room temperature. A total of $6001 \mathrm{~L}$ of sample was added to $26001 \mathrm{~L}$ of the reaction mixture in each cuvette. For the blank,

$50 \mathrm{mM}$ of acetate buffer ( $\mathrm{pH} 4.3$ ) was used in place of the sample. The decrease of absorbance at $734 \mathrm{~nm}$ elicited by the sample was 
measured after 15 min at $25^{\circ} \mathrm{C}$. TAC was expressed in $1 \mathrm{M}$ of trolox, ascorbic acid and gallic acid.

\subsection{Assay validation}

Calibration standards were daily prepared (all samples were determined in triplicate). The proposed methods were validated by linear range, limit of detection (LOD), limit of quantification (LOQ), precision and accuracy. LOD and LOQ were defined, respectively, as 3 and 10 times the standard deviation of 10 blank signals divided by the slope of the calibration plot (Miller \& Miller, 2000).

\subsection{Data analysis}

All results were expressed as mean \pm standard deviation. Data were tested using one-way ANOVA to determine the main effect of method, standard, flavours, vitamins and preservatives added to the waters, on the TAC of flavoured waters. Differences at $P<0.05$ were considered significant.

\section{Results and discussion}

\subsection{Descriptive statistics}

As can be seen in Fig. 1C $41.5 \%$ of water samples were still and $58.5 \%$ were sparkling or without gas. Labelled information also indicated the presence of several compounds, some of them with biological activity and others added for technological purposes. Among these, flavours, juice fruits, vitamins, acidifying agents, sweeteners and preservatives are present. However it was not indicated the amount of ingredient added to the water (see Table 2).

Lemon was the predominant flavour (Fig. 1D), present in all water brands (A to J). Twelve different flavours were used for the production of flavoured waters: Lemon (10 samples), mango, strawberry, raspberry and lime (2 samples each), pineapple, apple and orange (3 samples each), peach ( 4 samples), guava, melon and green apple (1 sample each)

About $50 \%$ of the samples had fruit juices or concentrates. According to the literature (Orak, 2009; Xu et al., 2008) fruits are an important source of antioxidants such as vitamin $\mathrm{C}$, carotenoids and phenolic compounds. Only flavoured waters from brands A, D and $G$ did not refer the addition of this kind of ingredient.
The majority of samples did not have vitamins (Fig. 1A). Only eleven samples had vitamins of B complex (7 samples) and C (4 samples). Vitamins B complex are important for DNA synthesis and in the cancer prevention (Zhang et al., 2008). It is also important to refer that vitamin $\mathrm{C}$ is an antioxidant with the capacity of protection against oxidative stress, and is a cofactor in several vital enzymatic reactions. According to the labelled information, the added amounts are very different amongst the several brands and some of them only refer its presence (Birch, Brasch, McCaddon, \& Williams, 2009; Weber et al., 1996).

Other bioactive compounds namely white and green teas, ginseng, ginkgo biloba and $\mathrm{L}^{-c a r n i t i n e}$ are present in some flavoured waters from different brands. Tea contains numerous components with antioxidant activity, such as polyphenols (catechins, epicatechin, epigallocatechin) and vitamins (Cabrera, Artacho, \& Giménez, 2006; Neyestani, Gharavi, \& Kalayi, 2009). Ginseng is an herbal medicine with antioxidant and anti-inflammatory activities (Radad, Gille, Liu, \& Rausch, 2006). Ginkgo biloba is rich in phenolics and flavonoids (Liu et al., 2007). L-Carnitine is an amino acid with antioxidant activity, neuroprotective and neurotrophic actions, positive actions on mitochondrial metabolism and stabilisation of intracellular membranes (De Grandis, 2007).

Phenolic compounds are correlated with antioxidant activity and seem to have an important role in stabilising lipid oxidation. The total phenolic contents (TPC) of this kind of waters was evaluated (data not showed). It was observed that all flavoured waters presented phenolic compounds in its composition. Like it was expected, natural waters did not have TPC. The highest TPC levels were from citrus fruits flavours (tangerine, lime and lemon) and from waters with bioactive compounds, like, tea, ginseng and gingko biloba.

In what concerns to preservatives and the information contained in the label, each sample can contain one (Sorbic acid and benzoic acid) or two preservatives (sorbic acid and benzoic acid; sorbic acid and dimethyl dicarbonate; benzoic acid and dimethyl dicarbonate) simultaneously (Fig. 1E).

Acidifying regulators are food additives added to change or maintain $\mathrm{pH}$; in this work the most used was the blend of citric acid and sodium citrate (31.7\%) (Fig. 1B). Citric acid is also an antioxidant, that can inhibit the decomposition of hydroperoxides by preventing their complexation with catalytic metal ions (Frankel, 2007)

Table 1

Main analytical features of the TAC assays.

\begin{tabular}{|c|c|c|c|c|c|c|c|c|c|c|}
\hline \multirow[t]{2}{*}{ Parameter } & \multirow{2}{*}{$\begin{array}{l}\text { FRAP }^{\mathrm{d}} \\
\text { Ascorbic } \\
\text { acid }\end{array}$} & \multicolumn{3}{|l|}{ TEAC } & \multicolumn{3}{|l|}{ ORAC } & \multicolumn{3}{|l|}{ TRAP } \\
\hline & & $\begin{array}{l}\text { Ascorbic } \\
\text { acid }\end{array}$ & $\begin{array}{l}\text { Gallic } \\
\text { acid }\end{array}$ & Trolox & $\begin{array}{l}\text { Ascorbic } \\
\text { acid }\end{array}$ & Gallic acid & Trolox & $\begin{array}{l}\text { Ascorbic } \\
\text { acid }\end{array}$ & $\begin{array}{l}\text { Gallic } \\
\text { acid }\end{array}$ & Trolox \\
\hline Range concentration (1M) & $1.00-24.7$ & $1.00-19.5$ & $0.50-4.0$ & $\begin{array}{l}1.00- \\
19.0\end{array}$ & $10.00-50.0$ & $\begin{array}{l}10.00- \\
56.0\end{array}$ & $\begin{array}{l}10.00- \\
50.0\end{array}$ & $1.00-11.5$ & $0.8-5.6$ & $\begin{array}{l}0.9- \\
9.4\end{array}$ \\
\hline Slope $(n=3)$ & 0.075 & -0.036 & -0.169 & -0.040 & 0.017 & 0.048 & 0.060 & -0.028 & -0.067 & -0.027 \\
\hline Intercept $(n=3)$ & 0.012 & 0.678 & 0.626 & 0.671 & 0.012 & 0.157 & -0.022 & 0.492 & 0.361 & 0.447 \\
\hline $\begin{array}{l}\text { Correlation coefficient } \\
\quad(n=3)\end{array}$ & 0.996 & 0.991 & 0.994 & 0.993 & 0.990 & 0.999 & 0.992 & 0.988 & 0.989 & 0.993 \\
\hline LOD (1M) & 0.023 & 0.049 & 0.010 & 0.044 & 0.104 & 0.037 & 0.029 & 0.063 & 0.026 & 0.065 \\
\hline LOQ (1M) & 0.078 & 0.163 & 0.035 & 0.147 & 0.345 & 0.122 & 0.098 & 0.210 & 0.088 & 0.217 \\
\hline \multicolumn{11}{|l|}{ Precision/accuracy } \\
\hline Added & 10.00 & 3.75 & 2.50 & 3.75 & 20.00 & 20.00 & 20.00 & 1.25 & 2.50 & 1.25 \\
\hline Found & 10.51 & 3.50 & 2.53 & 3.47 & 20.20 & 19.88 & 20.04 & 1.36 & 2.50 & 1.38 \\
\hline $\mathrm{RSD}^{\mathrm{a}}$ & 6.0 & 1.5 & 14.0 & 0.5 & 1.0 & 0.0 & 6.5 & 12.0 & 9.0 & 16.0 \\
\hline $\mathrm{RE}^{\mathrm{b}}$ & +5.10 & -6.67 & +11.20 & -7.47 & +1.00 & -0.60 & +0.20 & +8.80 & +0.00 & +10.40 \\
\hline $\mathrm{REC}^{\circ}$ & 105.1 & 93.2 & 101.2 & 92.5 & 101.0 & 99.4 & 100.2 & 108.6 & 100.0 & 110.0 \\
\hline
\end{tabular}

RSD: relative standard deviation.

${ }^{\mathrm{b}} \mathrm{RE}$ : relative error.

${ }^{\mathrm{c}}$ REC: recovery.

For $180 \mathrm{~min}$. 


\subsection{Method validation}

The linear relationship between absorbance (FRAP, TEAC, TRAP methods) or net area (ORAC method) and antioxidant concentration was evaluated for trolox, ascorbic acid and gallic acid. The corresponding analytical results are presented in Table 1 .

Linearity ranges were from 1.0 to $24.7,0.5$ to $19.5,10.0$ to 56.0 and 0.8 to $11.51 \mathrm{M}$ for FRAP, TEAC, ORAC and TRAP methods, respectively, depending on the standard. In general ascorbic acid and trolox provided wider linear ranges, while gallic acid showed linear behaviour along a narrower range of lower concentration.

The calculated LOD values ranged from 0.010 to $0.1041 \mathrm{M}$. LOQ values lied within 0.035 and $0.3451 \mathrm{M}$. Lowest LOD and LOQ values were found using gallic acid as standard antioxidant in TEAC method.

Precision and accuracy values are also shown in Table 1. Relative standard deviation (RSD) values ranged from $0.0 \%$ to $16.0 \%$, and confirmed the high precision of the method. Recovery (REC) and relative error (RE) values assessed the accuracy of the results; $\mathrm{RE}$ were always $<11 \%$ and recovery trials ranged from $92 \%$ to $110 \%$.

\subsection{TAC evaluation}

FRAP assay is a simple and inexpensive procedure that measures the total antioxidant level in samples. However, any com- pound with redox potential lower than that of the redox pair $\mathrm{Fe}(\mathrm{III}) / \mathrm{Fe}$ (II), can theoretically reduce $\mathrm{Fe}$ (III) to Fe(II), contributing to the antioxidant level of the sample (Prior et al., 2005).

TAC values obtained by FRAP method were based on different times of reaction, ranging between 0 and $250 \mathrm{~min}$ (Fig. 2). Ascorbic acid was always used as reference standard. Calibration curves were plotted for different times of reaction. TAC values were increased with the reaction time until $160 \mathrm{~min}$; signal stabilisation was reached after $180 \mathrm{~min}$ for all the water samples. Some authors indicated that FRAP redox reactions proceeded so rapidly that all reactions were complete within 4 and $6 \mathrm{~min}$, but in fact this is not always true. FRAP results can vary tremendously, depending on the time scale of analysis. Pulido observed that dietary polyphenols react more slowly and require longer reaction times (P30 min) for total quantification, and depending on the analysis time, the order of their reactivity was changed (Pulido et al., 2000). In this work the reduction of Fe(III) took at least $180 \mathrm{~min}$.

TAC values obtained using FRAP method were between 3.18 and 19.42 $1 \mathrm{M}$ for still water and 0.11-219 1M for sparkling water, considering $180 \mathrm{~min}$ for reaction time (Fig. 2). Still waters presented lower TACs than sparkling waters. The highest values were obtained in sparkling waters of brand $\mathrm{G}$ that were added of vitamin C. As expected, natural waters had the lowest TAC values sometimes below the LOD of the method. Lemon flavour produced the highest TAC values for all brands (exception for brand B). This

Table 2

Label information in flavoured water.

\begin{tabular}{|c|c|c|c|c|c|}
\hline Water & Ascorbic acid (labelled) & Flavour & Preservatives & Acidifying regulators & Sweeteners \\
\hline $\mathrm{A} 1$ & - & Lemon & Potassium sorbate & Citric acid & Acesulfame-K \\
\hline $\mathrm{A} 2$ & - & Mango & Sodium benzoate & Sodium citrate & \\
\hline A3 & - & Strawberry & & & \\
\hline B1 & - & Pineapple/orange & Potassium sorbate & Citric acid & Acesulfame K \\
\hline B2 & $\begin{array}{l}- \\
-\end{array}$ & Lemon & & & Aspartame \\
\hline $\mathrm{C} 1$ & - & Lemon/magnesium & $\begin{array}{l}\text { Potassium sorbate } \\
\text { Dimethyl dicarbonate }\end{array}$ & Citric acid & \\
\hline $\mathrm{C} 2$ & - & Apple/white tea & Potassium sorbate & & \\
\hline C3 & - & Pineapple/fibre & $\begin{array}{l}\text { Potassium sorbate } \\
\text { Dimethyl dicarbonate }\end{array}$ & & \\
\hline & - & & & & \\
\hline D1 & - & Apple & Sodium benzoate & Citric acid & Sucralose \\
\hline D2 & - & Orange/peach & Dimethyl dicarbonate & & Acesulfame-K \\
\hline D3 & $\begin{array}{l}- \\
-\end{array}$ & Lemon & & & \\
\hline E1 & - & Lemon & Potassium sorbate & Citric acid & Acesulfame K \\
\hline $\mathrm{E} 2$ & - & Orange/raspberry & Sodium benzoate & Sodium citrate & Aspartame \\
\hline E3 & - & Peach/pineapple & & & \\
\hline $\mathrm{E} 4$ & - & Guava/lime & & & \\
\hline $\mathrm{F} 1$ & - & Lemon/green tea & & Citric acid & \\
\hline $\mathrm{F} 2$ & - & Raspberry/ginseng & & & \\
\hline F3 & - & Peach/white tea & & & \\
\hline $\mathrm{F} 4$ & - & Mango/gingko beloba & & & \\
\hline F5 & $\begin{array}{l}- \\
-\end{array}$ & Melon/mint & & & \\
\hline G1 & $12 \mathrm{mg} / 250 \mathrm{~mL}$ & Lemon & Potassium sorbate & Citric acid & Sucralose \\
\hline G2 & & Lime & & & Acesulfame-K \\
\hline G3 & $12 \mathrm{mg} / 250 \mathrm{~mL}$ & Apple & Potassium sorbate & Citric acid & \\
\hline G4 & $\begin{array}{l}12 \mathrm{mg} / 250 \mathrm{~mL} \\
-\end{array}$ & Peach & Potassium sorbate & Citric acid & \\
\hline $\mathrm{H} 1$ & $30 \mathrm{mg} / 250 \mathrm{~mL}$ & Lemon & $\begin{array}{l}\text { Sodium benzoate } \\
\text { Potassium sorbate }\end{array}$ & Citric acid & Aspartame \\
\hline & - & & & & \\
\hline I1 & - & Lemon & Sodium benzoate & Citric acid & Aspartame \\
\hline $\mathrm{I} 2$ & - & Green apple & & & Sucralose \\
\hline I3 & $\begin{array}{l}- \\
-\end{array}$ & Strawberry & & & Aspartame \\
\hline J1 & - & Lemon & Potassium sorbate & $\begin{array}{l}\text { Citric Acid } \\
\text { Sodium citrate }\end{array}$ & $\begin{array}{l}\text { Aspartame } \\
\text { Acesulfame-k }\end{array}$ \\
\hline
\end{tabular}




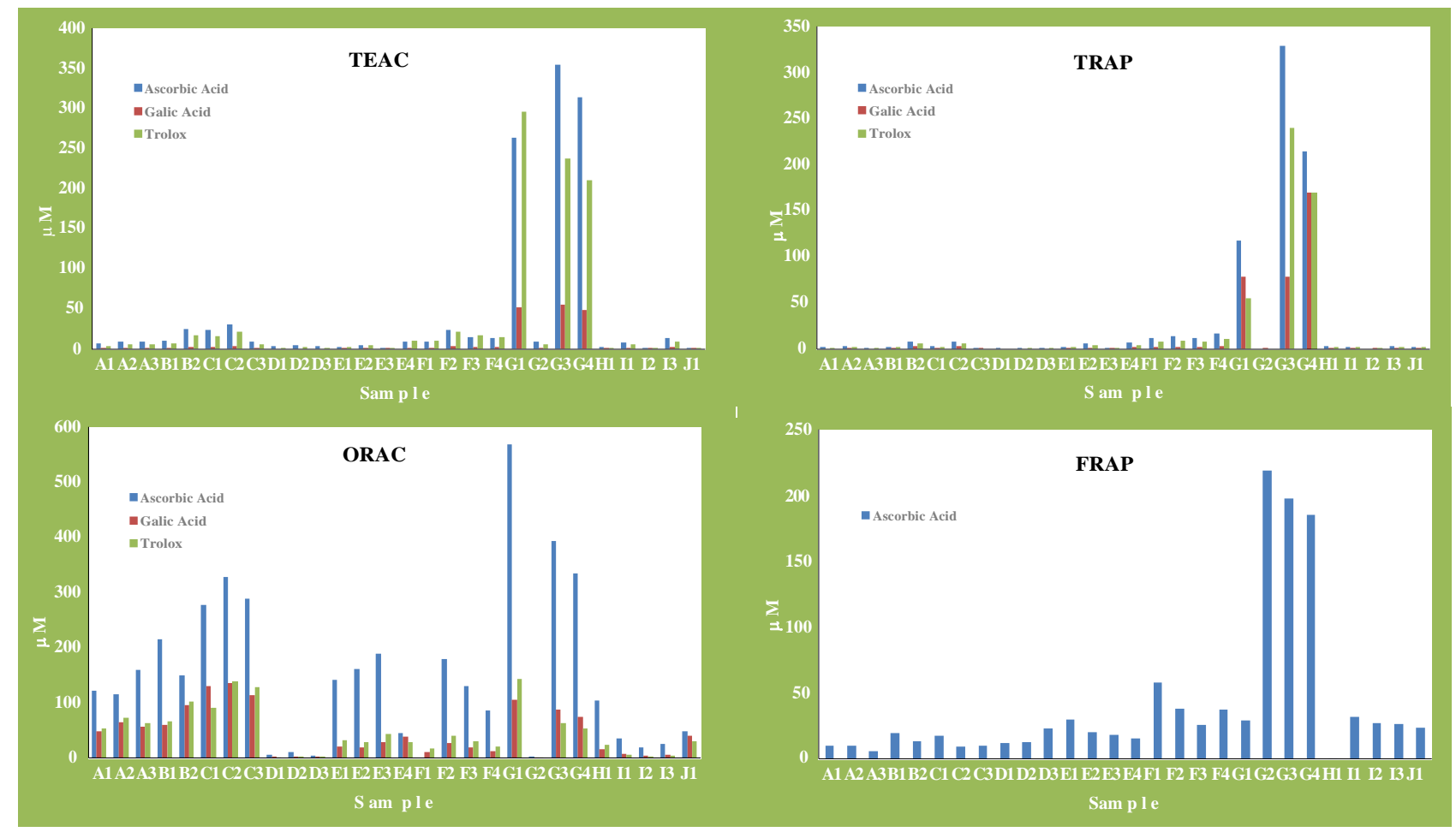

Fig. 2. TAC by TEAC, ORAC and TRAP methods expressed in $1 \mathrm{M}$ of ascorbic acid or gallic acid or trolox.

suggested that the addition of flavour and other ingredients to water increased their antioxidant content. According to labelled information, the following compounds were able to increase the TAC in the sample: ascorbic acid, citric acid, flavour, fruit juice and bioactive compounds. However, false positive results may occur by the concomitant production of $\mathrm{Fe}$ (II) by means of reducing compounds co-existing in the sample. In addition, compounds that absorb at the wavelength of the determination may interfere, causing overestimation of the FRAP value.

TAC values obtained using TEAC methods for all water samples are presented in Fig. 2. Thermodynamically, any compound that has a redox potential lower than that of ABTS ${ }^{+}$may react with the radical (Sánchez-Moreno, 2002). As the results obtained are related to each standard antioxidant and each antioxidant showed a specific kinetic behaviour, the results provided by this assay depend on the time of analysis. Since the experiments are carried out always for the same time, it is expectable that each sample has different TAC, according to the antioxidant used as standard. These compounds may be ascorbic acid, citric acid, flavours, fruit juice and bioactive compounds.

Generally, the addition of flavours increased TAC values of water samples, when compared to the natural ones. TAC values were higher when ascorbic acid was used. TAC values ranged from 0.05 to $354,0.03$ to 55 and 0.25 to $2961 \mathrm{M}$ using ascorbic acid, gallic acid and trolox standards, respectively. Natural waters had the lowest TAC values and some of these were below LOD. TAC values obtained in flavoured waters were similar with exception of those of brand G. As observed on FRAP method, TEAC values were higher in brand $\mathrm{G}$ for the three antioxidant standards, this could have been a result of the addition of vitamin $\mathrm{C}$.

Flavoured water samples with white tea, ginseng or gingko beloba as ingredients (from brands $\mathrm{C}$ and $\mathrm{F}$ ) have TAC values higher than other samples. Indeed there are some reports in literature indicating that tea has high antioxidant levels due to catechin components (Coyle, Philips, Morrisroe, Chancellor, \& Yoshimura, 2008). In general terms, the observed differences may outcome from the sample background and from the kinetics of the standard reaction. It is clear that flavoured waters have more TAC than non-flavoured ones, although the observed differences may not be attributed to a single compound or flavour. In addition, it is important to refer that this method has been criticised as the $\mathrm{ABTS}^{+}$radical is not representative of biomolecules and not even found in any biological system. However, this spectrophotometric assay is technically simple, which accounts for its application for screening and routine determinations.

The ORAC assay is one of the most common methods for assessing ROO' scavenging capacity. Because the protective effect of antioxidants is evaluated from the AUC, this method can be applied for antioxidants that exhibit distinct lag phases and also to those samples that have no lag phases accounting for kinetic differences within samples and standard. It takes into account the initial reaction rate and the total extent of inhibition, which includes the action of slow-reacting or secondary antioxidant products formed.

Fig. 2 displays the TAC contents in waters using ORAC method. Generally, TAC values were higher when ascorbic acid was used as calibration standard. The highest TAC value, like in the previously referred methods, was obtained in waters from brand G (for every antioxidant standards).

TAC values of still flavoured waters using ORAC method ranged from 0.55 to $328,0.52$ to $136,0.17$ to $1381 \mathrm{M}$ using ascorbic acid, gallic acid and trolox, respectively. Brand D had the lowest TAC results: the corresponding sample had no vitamins, preservatives, acidifying regulators and sweeteners.

ORAC results in sparkling flavoured waters expressed in ascorbic acid, gallic acid and trolox ranged from 2.0 to 569, 0.5 to 105 and 0.2 to $1441 \mathrm{M}$, respectively. As previously reported to other methods, the natural water samples did not display significant antioxidant capacity, and the addition of some ingredients to the water increased their TAC values. In addition, the highest TACs were obtained for samples with vitamin C. Other samples with high antioxidant capacity values contained vitamins of the B complex, which could have contributed for a TAC increase. 
TRAP method is the simplest one in terms of laboratorial experiment. TRAP results are presented in Fig. 2, and ranged from 0.05 to $8.371 \mathrm{M}$ in still waters and 0.13 to $3291 \mathrm{M}$ in sparkling waters.

Generally, still waters presented the lowest TRAP values when compared with the sparkling ones. When gallic acid was used for calibration, brand D displayed antioxidant capacities below the LOD of the method. In sparkling flavoured water, the highest values were obtained with samples with vitamina C from brand G. Natural waters did not show antioxidant capacity.

\subsection{Statistical evaluation}

Several factors influence the TAC values of flavoured waters, such as, method and standard, ingredients added to the water (flavour, vitamins, and preservatives) and commercial brand of the water. Their influence in the TAC level will be appreciated individually, facing the inherent limitations of a small sampling number (as commercially available). It is important to mention that tests made on waters of controlled chemical composition would be essential to confirm the statistical data presented below.

Considering the analytical method and analysing Fig. 2, the lower TAC values were obtained in TRAP method and the higher ones were provided by ORAC method. This behaviour was generally in agreement with Pulido and Prior (Prior et al., 2005; Pulido, Bravo, \& Saura-Calixto, 2000). Considering each standard separately, the Levene's test for equality of variances indicated that TAC values of each method were statistically different $(P<0.05)$. The only exception was TRAP method with trolox as standard $(P>0.05)$. The observed lack of correlation within all methods is also in agreement with $\mathrm{Ou}$ et al. (2002); that analysed freeze-dried vegetable samples and the results indicated that the FRAP and ORAC values did not correlate well. The same statistic behaviour was obtained in this work. The observed differences may be attributed to the differences in reaction mechanisms, oxidant and target/probe species, and reaction conditions for all TAC assays.

Regarding standards, ascorbic acid standard produced generally higher values than the other standards and gallic acid the lowest ones. SPSS test analysis also indicated that TAC values from different antioxidant standards were found statistically different $(P<0.05)$.

Flavours are added to plain water in order to attribute specific taste and smell. Technologically, flavours are added as fruit extracts, and fruits are rich in antioxidants. Typically, vitamin $\mathrm{C}$ is present in almost all fruits such as citrus, strawberry, pineapple; carotenoids in citrus fruit; tocopherol (vitamin E) in raspberry, melon and peach; and flavonoids in red fruit and nearly in all fruits. In this work, flavoured waters presented higher TAC levels when compared with the corresponding natural ones due to the increase of antioxidants by means of fruit extracts addition. One-way ANOVA for $95 \%$ level of significance confirmed that the presence of flavour influenced the TAC of the analysed samples $(P<0.05)$. TAC values from natural and flavoured waters obtained by TRAP method were not statistically different $(P>0.05)$, suggesting that this method maybe unsuitable for the present study.

Generally, higher TAC contents were obtained in apple, peach and lemon flavoured waters and lower values in guava and raspberry flavours. This behaviour was similar for all methods and antioxidant standards. Statistical analysis of flavour factor against TAC methods indicated however no statistical difference between all flavours $(P>0.05)$. This observation was most probably a result of the strong variability amongst all methods for each flavour.

Eleven flavoured water samples had vitamins C and B complex. Vitamin $\mathrm{C}$ was present in 4 samples, and vitamins of the $\mathrm{B}$ complex in 7 flavoured water samples; different kinds of vitamins $B$ were added to the commercial water: either a mixture of $\mathrm{B}_{3}$ and $\mathrm{B}_{12}(4$ samples); or a blend of $\mathrm{B}_{3}, \mathrm{~B}_{5}, \mathrm{~B}_{6}, \mathrm{~B}_{8}, \mathrm{~B}_{9}, \mathrm{~B}_{12}$ (3 samples).
Both vitamins $\mathrm{C}$ and $\mathrm{B}$ have antioxidant properties. Therefore, samples with these compounds should have higher TAC. Indeed, samples with vitamins $\mathrm{C}$ showed the highest TAC values, reaching 221, 314, 569, 329 $1 \mathrm{M}$ in FRAP, TEAC, ORAC and TRAP assays, respectively. The maximum TAC values for vitamins $\mathrm{B}$ were 30,31 , 328 and $81 \mathrm{M}$, respectively. There is a strong variability between these samples and some of them have low TAC. This wide range of TAC values points out no significant differences between samples with and without vitamins.

However, a straight comparison between samples where only vitamins are the difference in composition indicates otherwise. These results point out that vitamin produced a large increase on the antioxidant. This behaviour was obtained in all methods and all antioxidant standards. Statistical evaluation confirmed that the presence of vitamins influenced with $95 \%$ level of significance the TAC values of the flavoured waters $(P<0.05)$.

Preservatives are added to foodstuffs to preserve them. These compounds are not typically considered as antioxidant, for which it is not expected that their presence would change TAC values of samples. This assumption was confirmed statistically, either by grouping all samples or by comparing samples of similar background. Therefore, no statistical differences were observed in TAC values regarding the preservatives added to the flavoured waters $(P>0.05)$.

In the consumer's perspective, the brand is most probably the most important factor, leading to the selection of a specific product. Combining all results obtained, brand $\mathrm{G}$ seems to provide the highest antioxidant contents. Despite the corresponding waters show the higher TAC, this is most probably correlated to the vitamin $\mathrm{C}$ addition, and not to the brand itself. Confirming this, the only flavoured water from this brand that has no vitamins displays very low TAC. This sample is the responsible for three wide ranges of TAC values for this brand. In practical terms, this wide range of TAC values tends to eliminate the statistical differences between the commercial brands. Other brands have only single commercial flavoured water, providing no significance to their effect upon this study.

\section{Conclusions}

Flavours in waters had higher TAC than the natural ones from which they were obtained. The magnitude of this increase depended however on the method/standard used to estimate the TAC. Apple, pineapple and lemon waters provided in general the highest TAC values and guava and raspberry the lowest. There was however no statistical differences observed due to the strong variability between similar samples. The addition of vitamin $\mathrm{C}$ has been correlated to the highest increase in TAC. This has been confirmed statistically. The brand and the preservatives in the samples seem to display insignificant effects. In practical terms, it may be said that the additives in general are responsible for the TAC of flavoured waters, attributing vitamin $\mathrm{C}$ the main role for an increase in TAC. This information would be better confirmed if applied to a higher number of samples, but these are not commercially available.

\section{Acknowledgements}

The authors acknowledge IBeSa 2006/2007 for the financial support (MCruz) and REQUIMTE for hosting these experiments and providing the first draft of this paper.

\section{References}

Almajano, M. P., Carbó, R., Jiménez, J. A. L., \& Gordon, M. H. (2008). Antioxidant and antimicrobial activities of tea infusions. Food Chemistry, 108, 55-63. 
ANIRSF, Associação Nacional dos Industriais de Refrigerantes e sumos de fruta. (2009). Informar $\mathrm{n}^{\circ} 27$. From the website <www.anirs.pt> Accessed 01.06.10.

Araki, S., Kimura, T., Shimizu, C., Furusho, S., Takashio, M., \& Shinotsuka, K. (1999) Estimation of antioxidative activity and its relationship to beer flavour stability. Journal of the American Society of Brewing Chemists, 57, 34-37.

Augustin, W., Wiswedel, I., Noack, H., Reinheckel, T., \& Reichelt, O. (1997). Role of endogenous and exogenous antioxidants in the defence against functional damage and lipid peroxidation in rat liver mitochondria. Molecular and Cellular Biochemistry, 174, 199-205.

Benherlal, P. S., \& Arumughan, C. (2008). Studies on modulation on DNA integrity in Fenton's system by phytochemicals. Mutation Research, Fundamental and Molecular Mechanisms of Mutagenesis, 648, 1-8.

Benzie, I. F. F., \& Strain, J. J. (1999). Ferric reducing ability of plasma (FRAP) as a measure of "antioxidant power": The FRAP assay. Analytical Biochemistry, 239, 7076.

Benzie, I. F. F., \& Szeto, Y. T. (1999). Total antioxidant capacity of teas by ferric reducing/antioxidant power assay. Journal of Agriculture and Food Chemistry, 47, 633-636.

Birch, C. S., Brasch, N., McCaddon, A., \& Williams, J. H. H. (2009). A novel role for vitamin $\mathrm{B}_{12}$ : Cobalamins are intracellular antioxidants in vitro. Free Radical Biology and Medicine, 47, 184-188.

Cabrera, C., Artacho, R., \& Giménez, R. (2006). Beneficial effects of green tea - A review. Journal of the American College of Nutrition, 25, 79-99.

Cao, G., Alessio, H. M., \& Cutler, R. G. (1993). Oxygen-radical absorbance capacity assay for antioxidants. Free Radical Biology and Medicine, 14, 303-311.

Cao, G., \& Prior, R. L. (1998). Comparison of different analytical methods for assessing total antioxidant capacity of human serum. Clinical Chemistry, 44, 13091315

Castro, I. A., Rogero, M. M., Junqueira, R. M., \& Carrapeiro, M. M. (2006). Free radical scavenger and antioxidant capacity correlation of a-tocopherol and Trolox measured by three in vitro methodologies. International Journal of Food Sciences and Nutrition, 57, 75-82.

Coyle, C. H., Philips, B. J., Morrisroe, S. N., Chancellor, M. B., \& Yoshimura, N. (2008) Antioxidant effects of green tea and its polyphenols on bladder cells. Life Sciences, 83, 12-18.

Chen, W. J., Wang, J., Qi, X. Y., \& Xie, B. J. (2007). The antioxidant activities of natural sweeteners, mogrosides, from fruits of Siraitia grosvenori. International Journal of Food Sciences and Nutrition, 58(7), 548-556.

De Grandis, D. (2007). Acetyl-l-carnitine for the treatment of chemotherapyinduced peripheral neuropathy - A short review. CNS Drugs, 2, 9-43.

Ferreira, I. C. F. R., Baptista, P., Vilas-Boas, M., \& Barros, L. (2007). Free-radical scavenging capacity and reducing power of wild edible mushrooms from northeast Portugal: Individual cap and stipe activity. Food Chemistry, 100, 1511-1516.

Frankel, E. N. (2007). Antioxidants in food and biology facts and fiction. Bridgwater, England: Publisher Oily Press (Vol. 2, p. 231).

Ghiselli, A., Serafinni, M., Natella, F., \& Scaccini, C. (2000). Total antioxidant capacity as a tool to assess redox status: Critical view and experimental data. Free Radical Biology and Medicine, 29, 1106-1114.

Griffin, S. P., \& Bhagooli, R. (2004). Measuring antioxidant potential in corals using the FRAP assay. Journal of Experimental Marine Biology and Ecology, 302, 201211.

Halliwell, B. (2009). The wanderings of a free radical. Free Radical Biology and Medicine, 46, 531-542.

Huang, Z., Wang, B., Eaves, D. H., Shikany, J. M., \& Pace, R. D. (2009). Total phenolics and antioxidant capacity of indigenous vegetables in the southeast United
States: Alabama Collaboration for Cardiovascular Equality Project. International Journal of Food Sciences and Nutrition, 60, 100-108.

Lee, K. W., Kim, Y. J., Kang, N. J., Kim, J. H., Lee, S. J., Kim, D. O., et al. (2009). Improved assay for determining the total radical-scavenging capacity of antioxidants and foods. International Journal of Food Sciences and Nutrition, 60, 12-20.

Liu, X., Dong, M., Chen, X., Jiang, M., Lv, X., \& Yan, G. (2007). Antioxidant activity and phenolic of an endophytic Xylaria sp. from Ginkgo biloba. Food Chemistry, 105, 548554.

Miller, J. N., \& Miller, J. C. (2000). Statistic and chemometrics for analytical chemistry. London: Pearson Education.

Neyestani, T. R., Gharavi, A., \& Kalayi, A. (2009). Selective effects of tea extract and its phenolic compounds on human peripheral blood mononuclear cell cytokine secretions. International Journal of Food Sciences and Nutrition, 60, 79-88.

Orak, H. H. L. (2009). Evaluation of antioxidant activity, colour and some nutritional characteristics of pomegranate (Punica granatum L.) juice and its sour concentrate processed by conventional evaporation. International Journal of Food Sciences and Nutrition, 60(1), 1-11.

Ou, B., Hampsch-Woodill, M., \& Prior, R. L. (2001). Development and validation of an improved oxygen radical absorbance capacity assay using fluorescein as the fluorescent probe. Journal of Agriculture and Food Chemistry, 49, 4619-4926.

Ou, B., Huang, D., Hampsch-Woodill, M., Flanagan, J. A., \& Deemer, E. K. (2002). Analysis of antioxidant activities of common vegetables employing oxygen radical absorbance capacity (ORAC) and ferric reducing antioxidant power (FRAP) assays: A comparative study. Journal of Agriculture and Food Chemistry, $50,3122-3128$.

Pellegrini, N., Serafini, M., Colombi, B., Del Rio, D., Salvatore, S., Bianchi, M., et al (2003). Total antioxidant capacity of plant foods, beverages and oils consumed in Italy assessed by three different in vitro assays. Journal of Nutrition, 133, $2812-2819$.

Prior, R. L., Wu, X., \& Schaich, K. (2005). Standardized methods for the determination of antioxidant capacity and phenolics in foods and dietary supplements. Journal of Agriculture and Food Chemistry, 53, 4290-4302.

Pulido, R., Bravo, L., \& Saura-Calixto, F. (2000). Antioxidant activity of dietary polyphenols as determined by a modified ferric reducing/antioxidant power assay. Journal of Agriculture and Food Chemistry, 48, 3396-3402.

Radad, K., Gille, G., Liu, L., \& Rausch, W. D. (2006). Use of Ginseng in medicine with emphasis on neurodegenerative disorders. Journal of Pharmacological Science, $100,175-186$

Sánchez-Alonso, I., Jiménez-Escrig, A., Saura-Calixto, F. \& Borderías, A. J. (2007). Effect of grape antioxidant dietary fibre on the prevention of lipid oxidation in minced fish: Evaluation by different methodologies. Food Chemistry, 101, 372378.

Sánchez-Moreno, C. (2002). Review: Methods used to evaluate the free radical scavenging activity in foods and biological systems. Food Science and Technology International, 8, 121-137.

Weber, P., Bendich \& Schalch, A. (1996). Ascorbic acid and human health - A review of recent data relevant to human requirements. International Journal of Vitamin and Nutrition Research, 66, 19-30.

Xu, G., Liu, D., Chen, J., Ye, X., Ma, Y., \& Shi, J. (2008). Juice components and antioxidant capacity of citrus varieties cultivated in china. Food Chemistry, 106, 545551.

Zhang, S. M., Cook, N. R., Albert, C. M., Gaziano, J. M., Buring, J. E., Manson, J., et al. (2008). Effect of combined folic acid, vitamin B6, and vitamin B12 on cancer risk in women. A randomized trial. Journal of American Medical Association, 300, 20122021. 